\title{
Forest Fires Distribution in the Continental Area of Kavala
}

D Filiadis

${ }^{1}$ Forester MSc, Forest Service of Kavala, Terma Argirokastrou, GR-65404 Kavala, Greece

Received 10 April 2016; Accepted 15 May 2016

\begin{abstract}
The prefecture of Kavala has a long history of devastating forest fire events in both its continental part and Thasos Island. Forest fire records provide useful information on spatial and temporal distribution of forest fire events after statistical analysis. In this case study, the distribution of forest fires in the continental area of Kavala prefecture is presented for the period 2001-2014 through a series of simple-method statistics and charts/graphs. The number of forest fire events and burned area are presented on a month to month and annual basis. Burned forest area is categorized in three types (forest, shrub, meadow) according to Forest Services statistical records. Legislation changes on forest-shrub definition during the aforementioned period, could potentially affect the consistency of forest fire records. Thus spatial imagery was used for a more uniform interpretation of forest-shrub definitions on the forest fire spatial data. The most destructive wildfire years were 2013 and 2001, affected mainly by a respective single large forest fire event. On the opposite 2004, 2005 and 2010 were the least destructive years for the time period studied. Mediterranean type shrub lands were by far the most affected vegetation type that were also affected by the two single large wildfire event in 2001 and 2013. The 2014 had a zero forest fire record which coincides with a shift in the legislation implementation from the associated authorities regarding pasture management. The relationship between pasture management and forest fires has been widely recognized among scientists and land managers in Greece. Spatial distribution of forest fires in comparison with the recognized protected areas and the established infrastructure for fire protection was conducted using ArcGIS graphic environment and tools.
\end{abstract}

Keywords: Forest Service, Forest/shrub, Forest wildfires, Kavala, Statistical analysis

\section{Introduction}

Fires constitute a strong modification force on landscapes and are causing damages to natural ecosystems and to human livelihoods [1]. They are regarded an important disturbance factor globally [2] and part of the ecosystem dynamics in Europe [3] and the Mediterranean region [4]. The Mediterranean landscape has been the subject to many changes attributed to fires not only recently but also in historical times and even further backwards. In particular fires in the Mediterranean region have been used by men as a tool for land management and agriculture thus creating a characteristic mosaic pattern $[4 ; 5]$. Moreover, fires in the Mediterranean region contributed through species adaptation to the modification of the ecosystem characteristics [6;7].

Data from the European Forest Fire Information System (EFFIS) indicate that during the last three decades an average of 65,000 annual fire incidents in Europe were responsible for burning approximately 500,000 ha, from which $85 \%$ were in the European Mediterranean region [3]. In particular, southern Europe (France, Greece, Italy, Portugal and Spain) is characterized by catastrophic wildfire events that result in immense environmental and economic destructions [5;8] associated with desertification and ecosystem degradation [9].

Fires in Greece constitute the most dominant disturbance

\footnotetext{
*E-mail address: dimf8@hotmail.com ISSN: 1791-2377 @ 2016 Eastern Macedonia and Thrace Institute of Technology. All rights reserved.
}

factor of natural ecosystems and particularly forests. Since 1974 the country faces an increased number of forest fires incidents with a higher ratio of burned area per fire $(39.40$ ha/per fire) compared to other southern European countries (Spain 28.47, Italy 19.74 and Portugal 15.29) [10]. In general wildfires ignition is related to natural causes (lightning, volcanic eruption, sparks from rock falls, spontaneous combustion), and direct or indirect action of man [11]. Their spreading is more a result of a complex interaction among ignition sources, weather, topography, and vegetation type. In Greece, forest fires are attributed mainly to vegetation type, climatic conditions and arson [12]. The latter has been associated with a combination of an increased pressure for land use changes due to economic growth, with specific legislative regulations that allow land use changes of "pasture lands". Therefore the forest fire issue in Greece is regarded also a matter of political will to protect forests from land use changes $[12 ; 13]$.

The terms "forest" and "forest lands" are commonly been confused in Greek nomenclature. Iliadis et al. [12] stresses that the term "forest lands" includes a broad spectrum of vegetation structures including "forests", "partly forested and brushlands" and "pastures", covering about two thirds of the country's total area. However, from a legislative point of view "forests" and "forest lands" are distinctive structures of woody vegetation recognized accordingly to Law 998(1979) Art.3.

This is of particular importance as Law 998(1979) Art. $38 \& 41$ specifically ensure the protection of "forests" and "forest lands" after their destruction from fires or other causes, through their compulsory declaration in reforestation status that forbids land use changes. In addition, direct 
reforestation works are promoted where there is evidence of such a need after forest fires. The Forest Service in cooperation with Fire Service are the responsible administration authorities' for designing and implementation respectively of the fire-protection management plans. The Forest Service is also responsible for declaration of burned areas under reforestation status in case when forests or forest lands are destroyed. Both services keep records on forest fires and relevant statistics that are further used for identifying valuable information which is incorporated in fire protection management plans.

In the context of the aforementioned framework, the aim of this study is to find spatio-temporal distribution of the forest fires and their relation to the protected sites in the continental area of Kavala.

\section{Materials and Methods}

This study focuses on Forest Service statistical records on forest fires in the continental area of Kavala prefecture (excluding Thassos Island) for the time period 2001-2014. Part of the Eastern Macedonia and Thrace region, the area of 1,735 sq.km is bounded from river Strymonas to the West (40o 47'40' / $2351^{\prime} 30^{\prime \prime}$ '), river Nestos to the East (40 $50^{\circ}$ ' $\left.40^{\prime \prime} / 24^{\circ} 48^{\prime} 50^{\prime \prime}\right)$, Pangeon and Lekani mountains to the north ( $41^{\circ} 12^{\prime} 13^{\prime}, / 24^{\circ} 39^{\prime} 40^{\prime}$ ') and Aegean Sea to the south ( $40^{\circ} 43^{\prime} 08^{\prime}, / 24^{\circ} 3$ ' 20"') (Fig.1). According to CORINE database (Tab. 1) approximately two thirds of the total area is covered by natural vegetation (forest land, grassland) or semi-natural vegetation (cultivation with patches of natural vegetation). Forest lands (broad-leaved forest, sclerophyllous vegetation and transitional woodlandshrub) account for $48 \%$ of the total area $(83,869$ ha) while open areas (grasslands) and areas with sparse woody vegetation account approximately for another than $10 \%$ of the study area.

The Kavala prefecture has a long history of devastating fire events in both its continental part and Thasos Island. The latter have been declared as sensitive (higher risk) to forest fires with presidential Act 575/1980 while the former havenot (Fig.2). Devastating wildfire events occurred in both the Continental area of Kavala and Thasos Island in 1984, 1985, 1989 and 2000 burning approximately 34,000 ha of forested areas $[14 ; 15 ; 16]$. Consecutive statistical records (up to 2009) resulted both Thasos Island and Continental area of Kavala to be regarded as sensitive to forest fires (Fig. 3).

Forest fires records were further classified to different classes, depending on area burned, in order to be categorized according to relative destructiveness. Although it cannot be asserted that a 20 ha fire is twice more destructive than a 40 ha fire or even that a 19 ha fire is more destructive than a 21 ha fire, classification is an essential tool for better evaluation of data. A typical Forest Service forest fires reporting classification scheme uses five classes (0-1 ha, 1-5 ha, 5-100 ha, 100-500 ha, >500 ha). In order to achieve higher analysis of the 145 forest fires dataset an adaptation of the typical burned area classification scheme was implemented, with five classes (0-1 ha, 1-5 ha, 5-20 ha, 20-100 ha, >100 ha), for categorizing forest fires according to destructiveness (Tab. 2). For the 2001-2014 time period a total record of 145 forest fires in the continental area of Kavala has been classified in order to identify the annual number of forest fires (Fig. 5), burned area for each year (Fig. 6), forest fire events per month (Fig. 7), and area burned per month (Fig. 8).
In this case study, the distribution of forest fires in the continental area of Kavala prefecture is presented for the period 2001-2014 through a series of summarizing statistics and charts/graphs. Distribution of fire events on an annual basis is a common representation and statistical analysis method. Forest fire events and burned area are presented on a month to month and annual basis. Meteorological data relative to fire risk are also reviewed. Burned forest area is categorized in three types (forest, shrub, meadow) according to Forest Service statistical records.

The definition of "forests" and "shrublands" has been the subject of legislative acts and administrative instructions issued that ultimately altered the distinction among these two terms during the time period studied. Although numerical characteristics has been incorporated in the official definitions of forests and shrubs through Law $3208 / 2003$, interpretation guidelines has not been consistent through the time period. Moreover the definition of meadows in conjunction with forest and/or shrubs affects respectively the reporting on meadow, as this category could have been included on either forests or shrubs. Therefore, it is reasonable to assume that the difficulties in distinguishing forest vs. shrublands in a burned forestland landscape could only exacerbated as some of supportive evidence would have been destroyed by fire. In addition it should be considered that keeping tracks of a forest fire event is a far more constraint process that a general characterization of a broader area, since it is tied up strictly to the characterization of the burned area only. This differentiation clearly enhance the subjectivity of characterizations of forest vs. shrublands in a forest fire recording process.

Giving the possibility of inconsistent forest fire records regarding the distinction among the three terms, spatial imagery was used for manually interpretation and verification of forest fire records to the current legislative standards of Law 998/1998 (as applicable in Spring of 2015). Emphasis was given to land cover and vegetation density characteristics, using colored and black and white imagery from years 2007 and 1995 respectively, with imagery revealing only minimal differentiation in interpretation between forest-shrub-meadow incorporated in the forest fire records. Additionally, spatial information on protected areas, fire protection infrastructure and forest fires distribution was incorporated in ArcGIS map layers. Records of small, single tree fires, with an imperceptible destruction footprint where filtered out from further study.

\section{Results and Discussion}

For the 2001-2014-time period 145 forest fires have been recorded in the continental area of Kavala with a total burned area of 919,38 ha or 9,19 sq. km. Distribution of total burned area among the three interested vegetation types is presented in Fig. 4. Shrublands were by far the most affected vegetation type with $86 \%$, followed by forests $(8 \%)$ and meadows (6\%). The CORINE 2000 vegetation types that are associated with the burned area (94\%) of forests and shrublands are: (a) broadleaved forests (Quercus $s p$, Carpinus betulus, Fraxinus ornus, Ostrya carpinifolia) (b) sclerophyllus vegetation (Quercus ilex, Olea sylvestris) and (c) transitional woodland-shrub. The burned area of meadows $(6 \%)$ is in straight analogy with the CORINE 2000 land cover type of natural grasslands $(6.63 \%)$.

Data indicate that most destructive years in terms of area burnt during the time period of the study were 2001 and 
2013. Records from both years were affected by a singlelarge catastrophic fire event of class V (over 200 ha each). On the opposite 2004, 2005 and 2010 were the least destructive years during the time period studied. Most fire events per year (at least 10) were observed in 2001, 2002, 2007, 2008, 2009, 2011 and 2013. Minimum fire events per year (5 or less) were observed in 2004, 2005, 2010, and 2013 while in 2014 there was a zero forest fire record. The latter observation coincides with a shift in the implementation, from the associated authorities, of legislation related to the compulsory declaration of "reforestation" status of burned forestlands and their subsequent exclusion from pasture management plans and pasture subsidies.

Although forest fires occurrence is a complex issue that cannot be attributed solely to a single one parameter (in this case pressure from land uses), the linkage between forest fires and grazing has been discussed in many scientific investigations $[17 ; 18 ; 19 ; 20]$, as a significant land use policy subject in the Mediterranean basin. It should be noted however that forest fire risk is influenced by many variables, which have a wide range of spatial and temporal variability. Variables that do not change in a short lapse of time (fire history, fuel types, population, topography and soil types) are incorporated to long-term or structural indices while those varying in short period of time (vegetation status, meteorological conditions) are incorporated to dynamic indices [6]. Therefore, statistical evidence on forest fire records should be investigated from a multiple physical and social perspective, in order to substantiate the importance of each parameters.

In this perspective the effect of increasing temperatures recognized by IPCC [21] should also be incorporated to the interpolation of forest fires statistics. For example, local meteorological data (Fig. 9) indicate a generally increasing trend of mean surface temperature, during the last 30 years, which is in accordance with the ascending mean global temperature trend described by IPCC reports. In addition, reduced mean temperature in 2005 and 2011 coincides with reduced burned area. However, the catastrophic fire events of 1984, 1985 and 1989 occurred during a period with low mean temperature (Fig. 7). In this respect time series analysis for larger samples of fires is necessary in order to conclude the relationship between wildfires and temperature.

Local meteorological data spanning from 2001-2010 were used for constructing the ombrothermic diagram of the study area (Fig. 10). The latter depicts the dry months of the year, which refer to the period when precipitation is less than twice of the temperature, i.e. $\mathrm{P}<2 \mathrm{~T}$. The meteorological data (Fig. 10) indicate a 4-month dry period that extends from late May till late September and culminates in August when higher water deficit conditions are observed. Monthly distribution of forest fires indicated a seasonal variability that is in accordance with local meteorological data (Fig. 10). August was by far the most destructive month of the years examined with 666.75 ha (or $72.52 \%$ ) of total burned area (Fig. 8). Also August was the month with the most fire events, followed by July and September (Fig. 7).

Finally, an ArcGIS map was built in order to illustrate the spatial distribution of forest fires, in relation to protection areas and anti-fire infrastructures (Fig. 11). The study area accommodates many areas under protection status, associated with international legislation (SPA and SCI sited of Natura 2000 network, Ramsar wetlands) and national legislation protection status (Aesthetic forests, Wildlife Reservers). Protected areas are distributed in the following geographic locations: the Pangeon Mountain in the west (SCI, SPA, Wildlife Reserve), the Symvolon Mountain and the periurban forest of Kavala (SPA, Aesthetic Forest, Wildlife Reserve) in the central area, the Kestene Mountain (Wildlife Reserve) in the north east, and the Riparian forest on Nestos Delta (SCI, SPA, Aesthetic Forest, Ramsar Wetland) to the far east. Due to the multitude of protection statues there is an overlapping protection in many areas especially in Nestos Delta.

The spatial distribution of wildfires in relation to distance from protected areas was illustrated with the ArcGIS Spatial Statistics Toolbox. The Natura 2000 sites, the Wildlife Reserves, and the Aesthetic Forests was used for constructing a filter of wildfire spatial information (a mixture of 455 sq.km out of 1,735 sq. $\mathrm{km}$ or $26.22 \%$ of the study area). The wildfire events were classified in six categories according to their occurrence within protected areas or within a distance of 1,2,3,4 and $5 \mathrm{~km}$ from them (Fig. 12). According to this classification the number of fire events occurred within the protected areas layer was found to be $28.97 \%$ while the extent cover of the protected areas layer $(26.22 \%)$. In contrary the relative burned area within the protected areas layer was found to represents only $8.47 \%$ of the total burned area. The aforementioned differentiation (Fig. 13) between the percentage of forest fires number and the relative percentage of burned area was also observed in the other wildfire classes with a distance of $1,2,3,4$ and 5 $\mathrm{km}$ from protected areas. The above observation is an indication that forest fires within or near the protected areas have smaller area burned and therefore were less destructive during the time period examined. However, such an interpretation needs further investigation in order to recognize robust explanation scenarios. For example the availability of forest fire protection infrastructure and the implementation of forest fire management plans that pay particular importance to protected areas could have potentially contributed to minimizing the destructiveness of forest fires near to areas under protection status.

Infrastructure for protection from wildfire events in the study area is mostly consisted from water reservoirs and fireprevention zones. Using the ArcGIS directional distribution tool their geographic distribution was found to be dispersed mainly in a west to east axis starting from East Pangeon Maountain, to the Aesthetic Forest of Kavala and more eastwards to the Kavala and Kestene Wildlife Reserves, and finally to the northernmost mountainous areas of the river Nestos watershed. The lowland area of Riparian forest of Nestos delta are in proximity with abundant water resources and therefore no water reservoirs or other infrastructure are established there. Fire-prevention zones are linear infrastructures intended to disrupt the continuity of flammable material and are found exclusively on Symvolon Mountain, on the Aesthetic Forest of Kavala and the Kavala Wildlife Reserve.

The spatial distribution of the most severe forest fire events was further analyzed using the ArcGIS Spatial Statistics Toolbox. It was found that from the total of 145 forest fires that burned 919.38 ha there was only 8 exceeding 10 ha of burned area, resulting to the destruction of 612,96 ha or $2 / 3$ of the total burned area. Using again the ArcGIS directional distribution tool the geographic distribution of the big forest fires (>10 ha) was found around the north central part of the study area, distinctively northern from the geographic distribution pattern of water reservoirs (Fig. 14). Moreover that the aforementioned area of the most destructive wildfires hosts 6 out of 8 forest fires ( $>10$ ha) 
during the studied period with a total of 548.45 ha area burned (or $60 \%$ ). This geographic area is characterized not only from a deficit in forest fire protection infrastructure but also from a poorly developed road network, as well as greater distances from Fire Service main stations in Kavala and Chrysoupoli.

\section{Conclusions}

A spatiotemporal distribution of forest fires in the continental area of Kavala was carried out in this study. The use of spatial imagery in ArcGIS environment allowed the control of consistency in burned vegetation types reporting. According to the statistical records forest and shrubs accounted for $94 \%$ of the burned area. Forest fires were classified in five classes according to their extent. Seasonal variability of fire events within years was typical with August been the most destructive month of the year. Variability among years was recognized with identification of the most destructive years. A zero forest fire record during 2014 coincide with a shift in the legislation implementation relating to forest and pasture management. Distribution of protected areas was considered in conjunction with the distribution of fire protection infrastructure and found to be distinct. In addition, the geographic distribution direction of the most destructive forest fires were found to differentiate from the geographic distribution direction of fire protection infrastructures. Future GIS and remote sensing methodologies as well as geospatial analysis techniques could potentially attribute to further analyzing the forest fire data in terms of vegetation types, protection areas, and anti-fire infrastructure proximity altogether.

This paper was presented at International Conference titled "Frontiers in Environmental and Water Management", that took place March 19-21 ${ }^{\text {st }}$ 2015, at Kavala Greece.

Acknowledgements: The author would like to thanks the administration of the Kavala Forest Service for providing access to forest fire records and other related information material. Also the author gratefully acknowledges Lecturer Dr George Zaimes from Eastern Macedonia and Thrace Institute of Technology, Department of Forestry and Natural Environment Management for his specialized advises and support.

\section{References}

1. L. Bohórquez, I. Gómez, F. Santa, Procedia Environmental Sciences, 7(0), 389-394 (2011).

2. R. A. Shakesby, S. H. Doerr, Earth-Science Reviews, 74(3-4), 269307 (2006).

3. J. San-Miguel-Ayanz, E. Schulte, G. Schmuck, A. Camia, P. Strobl, G. Liberta et al., Comprehensive Monitoring of Wildfires in \{E\}urope: The \{European Forest Fire Information System\} (\{EFFIS $\})$. In: Approaches to Managing Disaster - Assessing Hazards, Emergencies and Disaster Impacts. J Tiefenbacher editor: InTech. (2012).

4. G.J. Pausas, V.R.Vallejo, The role of fire in European Mediterranean Ecosystems. In: Chuvieco E. (ed.) Remote sensing of large wildfires in the European Mediterranean basin, pp.3-16. SpringerVerlag,

(1999). http://www.sfu.ca/ ianh/geog315/readings/PausasVallejo1999.pdf Last accessed 10/5/2015

5. J. San-Miguel-Ayanz, E. Schulte, G. Schmuck, A. Camia, Forest Policy and Economics, 29(0), 19-25 (2013).

6. P. Riera, J. Mogas, Forest Policy and Economics, 6(6), 521-528 (2004).

7. R. A. Shakesby, Earth-Science Reviews, 105(3-4), 71-100 (2011).

8. I. Fuentes-Santos, M.F. Marey-Pérez, W. González-Manteiga, Journal of Environmental Management, 128(0), 30-42 (2013).

9. A.T. Vafeidis, N.A. Drake, J. Wainwright, CATENA, 70(3), 396-409 (2007).

10. L.S. Iliadis, Environmental Modelling \& Software, 20(5),613-621 (2005).

11. L. Serra, P. Juan, D. Varga, J. Mateu, M. Saez, Environmental Modelling \& Software, 40(0), 235-244 (2013).

12. L.S. Iliadis, A.K. Papastavrou, P.D. Lefakis, Forest Policy and Economics, 4(1), 43-54 (2002).

13. A. Papastavrou, Social financial and cultural aspects and legal frames for forest fires in Greece. Aristotle University of Thessaloniki (1995).

14. Guidelines for Anti-Fire Management Plans Ministry of Environment, Energy and Climatic Change, (2011).

15. Eleftheriadis D. Nikolaos. The Forests of Thassos, Thasiaka, Vol. $\mathbf{8}^{\text {th }}$ http://www.library.teikav.edu.gr/thasiaka/thasiakafiles/t8/t8a09.pdf. Last accessed 17/4/2016

16. K. N. Rishmawi and Ioannis Z. Gitas, "Burned area mapping on the Mediterranean island of Thasos using low, medium-high and very high spatial resolution satellite data", Proceedings of the first annual conference of the Remote Sensing and Photogrammetry
Society (RSPSoc 2001): Geomatics, Earth Observation and the Information Society. Remote Sensing and Photogrammetry Society, London, UK, pp. 408-420 (2001).

17. Y. Birot, Our life with forest fires: a Scientific View. EFI Discussion Paper $15 \quad$ (2009). http://www.ypeka.gr/LinkClick.aspx?fileticket=LDCNIC24i2M\%3 D\&tabid=718. Last accessed 10/5/2015.

18. V.P. Papanastasis, Land degradation caused by overgrazing and wildfires and management strategies to prevent and mitigate their effects, pp. 187-198. In: Desertification in Europe: mitigation strategies, landuse planning (G. Enne, Ch. Zanolla and D. Peter, eds). European Commission, EUR 19390, Luxembourg (2000).

19. V.P. Papanastasis, New views about the role of livestock husbandry and grazing in the natural environment. (2010). http://aeiforia.for.auth.gr:8080/Portals/0/Papanastasis.pdf. Last accessed 10/5/2015

20. F. Rego, E. Rigolot, P. Fernandes, C. Montiel, J. Sande Silva, Towards an Integrated Management of Forest Fires. EFI Policy Brief 4. European Forest Institute Global Fire Monitoring Center (GFMC) (2010). http://www.fire.unifreiburg.de/programmes/natcon/Fire-Paradox-Policy-BriefIntegrated-Fire-Management-GRE.pdf. Last accessed 10/5/2015

21. IPCC Climate Change, The Physical Science Basis. Contribution of Working Group I to the Fifth Assessment Report of the Intergovernmental Panel on Climate Change [Stocker, T.F., D. Qin, G.-K. Plattner, M. Tignor, S.K. Allen, J. Boschung, A. Nauels, Y. Xia, V. Bex and P.M. Midgley (eds.)]. Cambridge University Press, Cambridge, United Kingdom and New York, NY, USA (2013) 